\title{
EDITORIAL
}

\section{Special Section: Palliative Care as a Public Health Issue in the Developing World}

Journal of Public Health Policy (2007) 28, 26-27.

doi:I0.1057/palgrave.jphp.3200I I0

In the spring of 2006 , a colleague inquired whether we considered palliative care to be a public health issue. We responded that medical care is part of public health - at least where interventions are organized to reach large portions of the population - and promise favorable impact on health. As palliative care allows patients who have lost functionality to pain to regain it, and, thus, to carry on meaningful and productive lives, sometimes for years, it plays an especially important role in developing countries plagued with HIV/ AIDS and cancer. As these diseases strike children and parents of children as well as the elderly, there is much to be gained for the patients, their families, communities and societies. As palliative care offers gains in well being, we said we would welcome an article addressing palliative care as a public health issue, especially with a focus on the developing world. We do not know if the submission that arrived several months later, which appears just below (Palliative Care: A Public Health Priority in Developing Countries by Ruth Webster and colleagues) is related to the initial conversation, or merely a coincidence. In any event, we sent the submission out for review. Among the several reviewers, we sought an expert in Uganda as the Webster article pointed to that country as an example of promising developments in Africa.

I found an opportunity to visit the Kampala-based Hospice Africa when I was in Uganda some time after JPHP had accepted for publication the initial, peer-reviewed article. The visit motivated us to seek the commentaries and the viewpoint that follow, and these have not undergone peer review. Appearing first among them is a commentary by Dr.s Jagwe and Merriman in Uganda - the only country in Africa where, in the context of HIV/AIDS, palliative care is classified in the nation's health strategic plan as an essential clinical 
service. Next, the former Chief of Cancer at the World Health Organization, Dr. Jan Stjernsward, offers a world tour of palliative care strategic highlights for JPHP's general readership in a Viewpoint emphasizing the issues most pertinent to developing countries. Dr. Olaitan Soyannwo adds his perspective from Nigeria, commenting on Webster et al, the WHO program, and on developments in medical curricula in Nigeria. Faith Mwangi Powell, who leads the African Palliative Care Association, comments on innovative approaches to achieve government acceptance of opioid use for pain management and new methods to replace opioid consumption measurements as an indicator of palliative care development. We complete the section with my account of a visit to Hospice Africa in Kampala - a base of service locally, and for education and advocacy across all of Africa. 